\title{
COMMENTARY
}

\section{The improbable challenge of managing students' challenging behaviors in schools: Professional reflections from a 30 year career}

\begin{abstract}
John W. Maag
Abstract: Managing students' challenging behaviors is one of the most difficult tasks teachers face. Many teachers, during their training, were never required to take a class in behavior management. Consequently, it does not come naturally for teachers to manage students' challenging behaviors and will rarely be effectively addressed for two reasons: (1) certain teacher characteristics regarding behavior management and (2) particular dimensions of school culture. The philosophical linchpin is not an inability of teachers to learn effective behavior management techniques, but rather what they believe about the process. This article addresses these variables from my professional experiences and reflections spanning a 30-year career as a special education teacher, licensed psychotherapist, and university professor. Throughout this article I will embed alternative ideas about managing students' behaviors more effectively.
\end{abstract}

Keywords: students' challenging behaviors, behavior management

\section{Introduction}

For decades, strategies for managing students' challenging behaviors has always been the number one topic on which teachers want more inservice training ${ }^{[1-3]}$. Yet preservice teachers receive very little to no formal undergraduate training in behavior management or what is sometimes referred to as applied behavior analysis. Grant it, almost every undergraduate teacher training program in special education requires a behavior management course. Conversely, very few, if any, general education undergraduate teacher training programs at the elementary or secondary levels offer any courses in behavior management or applied behavior analysis ${ }^{[4]}$. Related content such as social skills training and multi-tiered systems of support (MTSS) are rarely part of a general education teacher training curriculum-even though schools have moved to tiered approaches for academics and behavior $^{[5-7]}$. Behavior management plays a central role in both these areas. Students in general education teacher training programs may get some information or even an

Received: August 6, 2020 Accepted: August 28, 2020 Published: September 3, 2020 Correspondence to: John W. Maag, Department of Special Education and Communication Disorders, University of Nebraska-Lincoln, Lincoln, NE 68583-0732, USA; Email: jmaag1@unl.edu

Citation: Maag JW. The improbable challenge of managing students' challenging behaviors in schools: Professional reflections from a 30 year career. Adv Educ Res Eval, 2020, 2(1): 93-100.

Copyright: (c) 2020 John W. Maag. This is an open access article distributed under the terms of the Creative Commons Attribution License, which permits unrestricted use, distribution, and reproduction in any medium, provided the original author and source are credited. entire course on classroom management, but that is very different than behavior management - the former focuses on techniques for arranging classroom space, developing classroom rules, managing transition time, handling classroom materials, and managing students' paperwork whereas the latter focuses on the traditional operant AB-C model: $\mathrm{A}=$ analyzing antecedents, $\mathrm{B}=$ identifying response class, $\mathrm{C}=$ determining contingencies of reinforcement $^{[8]}$.

There is a disconnect between for the need for general education teachers to be trained in behavior management strategies and the lack of preservice training programs requiring, or even offering, these courses. In an attempt to understand some of the implications of this disparity, I wrote an article approximately 20 years ago entitled "Rewarded by punishment: Reflections on the disuse of positive reinforcement in schools" that was published in the journal Exceptional Children ${ }^{[9]}$. The first part of the title, "rewarded by punishment" was a satiric rejoinder to Alfie Kohen's book Punished by Rewards ${ }^{[10]}$ in which he makes the erroneous assumption that "rewards" and "reinforcement" are synonymous. The point I was making was that teachers much prefer to use punishment-or what they perceive is punishment, particularly exclusionary practices - than positive reinforcement because the former is so negatively reinforcing. The reason is simple and understandable. Individuals are negatively reinforced when they perform a behavior that terminates something they find unpleasant or aversive. That behavior, whatever 
it was, is now more likely to be performed in the future. Specifically, teachers find students' misbehavior to be unpleasant. The behavior of removing the student from the classroom effectively terminates the unpleasantness of that student's misbehavior. Consequently, a teacher is more likely in the future to remove a misbehaving student, and as I have observed over the years, for less and less severe infractions ${ }^{[11]}$.

At first, I never realized how impactful the "Rewarded by Punishment" article would become_-having been cited 413 times and even now, almost two decades later, it was cited over 20 times in 2018 alone. Sadly, that article and others like it from extremely influential authors such as Saul Axelrod ${ }^{[12]}$ when he penned the following poem, are ignored or demonized:

"ABA gets little respect

Though it has had a major effect.

You would think Skinner

Had turned out a winner,

Instead of a functional reject" (p. 247)

After over 30 years in the field teaching courses in behavior management using the textbook I authored, and given countless inservice trainings and seminars, I have reached the conclusion that managing students' behaviors is, and always will be, the biggest challenge teachers and schools face and one that is rarely, nor will be, consistently and effectively addressed for two reasons: (1) certain teacher characteristics regarding behavior management and (2) particular dimensions of school culture. The philosophical linchpin is not an inability of teachers to learn effective behavior management techniques, but rather what they believe about the process. This article addresses these variables from my professional experiences and reflections spanning a multi-decade year career as a special education teacher, licensed psychotherapist, and university professor. Throughout this article I will challenge teachers to accept and adopt alternative ideas and techniques for managing students' behaviors more effectively.

\section{Teacher characteristics that impede using effective behavior management}

It is important to understand that addressing certain characteristics are not meant to be a personal attack on teachers' commitment to students, their learning, and overall well-being. Rather my goal is to identify teacher beliefs, misunderstandings they hold regarding behavioral terms, and some personality traits that serve as impediments to improving students' behavior. By doing so, I hope to have teachers reflect more deeply about pre- conceived notions that may impede using more effective methods for managing students' challenging behaviors.

\subsection{Teacher beliefs about misbehavior}

There are many teacher misbeliefs about students' challenging behaviors and how to address them but two prominently and adversely impact the effectiveness of behavior management. First, teachers expect students to be good and react to them when they are bad. Second, teachers do not think it is fair for some students to receive positive reinforcement when most others are intrinsically motivated and behave well without it.

Expect good behavior and react to bad behavior. One of the simplest, and effective, ways to improve a classroom of students' behaviors is to catch them being good and provide verbal praise, a smile and nod, or light squeeze or pat on the shoulder. One does not need an advanced course in applied behavior analysis nor extensive knowledge of principles of behavior to consistently implement this technique. Several years ago I described a simple procedure to help teachers catch students being good $^{[13]}$. Teachers create a self-monitoring sheet in which students' names appear in a far left-hand column. The days of the week appear across the top horizontal line. This creates a "matrix" of lines that has five boxes for each student's name corresponding to each school day of the week. The teacher then sets her phone to vibrate randomly between 10 and 90 seconds (a device called the MotivAider ( $\mathrm{B}$ can be used instead). When the device vibrates the teacher scans the room and verbally praises a child (e.g., "Nice writing", "I like the way you're sitting", "Thank you for having your eyes on the book", etc.). The teacher then makes a tally mark in the matrix cell next to that student's name. At the end of the week the teacher can identify patterns to determine which students received the most reinforcement and then alter her praise accordingly. Not coincidentally, students who had previously displayed the most challenging behaviors should have the most tally marks. The reason is simple: They are used to receiving only negative attention and negative attention is better than no attention at all and can also be highly reinforcing for these students ${ }^{[8]}$. We want to turn around that pattern from negative to positive.

What could be easier, more discrete, and require less work? The self-monitoring sheet could even be transposed on a tablet which most teachers and students carry with them during the course of a day and when cued, the teacher can touch the cell for the student who just received praise. Yet few teachers make a concerted effort to catch students being good. The reason has to do with their belief that students are expected to be good, 
and consequently, ignore them, but react to them when they misbehave, often administering a verbal reprimand, and as I indicated previously but cannot overstate, some students find that negative attention highly reinforcing.

Positive reinforcement is not fair. Because teachers expect students to be good and react to them when they are bad, there is a tendency for them to eschew positive reinforcement as being unfair to other students who do not need that type of external motivation. A common statement they make is "Other students don't need reinforcement to behave well so why should I use it with the two students who don't behave well when I can remove them from the room?" What these teachers are failing to understand is that for some students, positive reinforcement constitutes an accommodation. A related teacher question is "Don't you think there comes a time when I should expect this student to behave as well as others without always needing external rewards?" That spurious logic would be tantamount to a teacher saying, "Don't you think there comes a time I should expect this student who wears glasses to see just as well as others without them?" The reality is that positive reinforcement and the behavior management techniques on which it is delivered are accommodations just as real as making aisles wider between rows for a student in a wheelchair.

\subsection{Teacher misconceptions about important terms}

Teachers have glaring misconceptions regarding the terms "discipline", "positive reinforcement", "rewards", and "punishment". Many teachers think discipline and punishment are synonymous while the same error exists for positive reinforcement and rewards. The word "discipline" simply means training expected to produce moral or mental improvement. A key word in this definition is improvement which entails increasing skills or competence in a certain area. Consequently, discipline is not eliminating behavior such as the case with punishment but rather increasing (i.e., improving) positive behaviors. A "reward" may or may not function as reinforcement or even punishment depending on its subsequent consequences. At a basic level, a reward (or prize) is a tangible sign of merit or accomplishment, such as a trophy, or a blue ribbon at a fair, which is much different than positive reinforcement. Those two misconceptions lead to even more severe ones when examining the terms positive reinforcement and punishment.

There are two underpinning facts about reinforcement and punishment that define them. First, both are not "things" but rather "effects". If the effect is that behavior increases then that consequence (i.e., what comes after a behavior is performed) can be considered reinforcement. Conversely, if the effect is to decrease or eliminate behavior then the consequence is punishment. Neither are tangible. We cannot see reinforcement or punishment any more than we can see gravity. What we can observe are their effects. For example, a student makes six animal noises in five minutes and the teacher sends him to a timeout chair in the back of the classroom. For the next five minutes in the timeout chair the student makes nine animal noises. The consequence of being sent to the timeout chair functioned as positive reinforcement because the effect was to increase the number of animal noises, which poses the rhetorical question: Why in the world would a teacher want to reinforce a student for making animal noises? Relatedly, teachers frequently say, "I've tried reinforcement and it doesn't work". If a consequence does not have the effect of increasing behavior then it was not a reinforcer. Punishment operates the same way. If punishment was working for a teacher she would be using it less rather than more often in the future because the misbehavior would have decreased or been eliminated and thus negate the continued use of that consequence. Unfortunately, teachers present the same negative consequence repeatedly with the same result - no change in behavior.

The second underpinning of reinforcement and punishment is that they are naturally occurring phenomenon just as is gravity. B. F. Skinner did not "invent" reinforcement and punishment. Rather he discovered them just like Isaac Newton discovered gravity. Just like gravity, punishment and reinforcement can be used in either good or bad ways. Dropping large stones or bowling balls on cars from an overpass is a bad use of gravity. The previous example of the teacher putting the student in a timeout chair was a bad use of reinforcement. Teachers will frequently say that they do not believe in using positive reinforcement. This statement begs the question "Positive reinforcement is naturally occurring in your classroom and would you rather preplan its use to increase appropriate behaviors or let it occur haphazardly and run the risk of it increasing inappropriate behaviors?"

\subsection{Teacher personality traits}

There are specific and general teacher personality traits that impact, positively or negatively, their ability to manage students' challenging behaviors effectively. A specific trait would be teachers' self-efficacy beliefs regarding educational practices and student achievement. A general trait would be a teacher's individual temperamental characteristics developed over time.

Teachers' self-efficacy. Gaudreau, Royer, Frenette, 
Beaumont, and Flanagan ${ }^{[2]}$ conducted a brief review of teachers' self-efficacy and how certain beliefs impact their pedagogical practices. The research they reviewed is quite illuminating. The term "self-efficacy" was first described by Bandura ${ }^{[14]}$ and refers to one's beliefs of how effectively their own behaviors can achieve a certain goal. In the current context, teachers' perceptions of students with behavioral difficulties and their own self-efficacy can impact their choice of interventions, willingness to work with these students, and what students they think will succeed. Gaudreau and her colleagues also found the research suggests that teachers with greater perceived teaching self-efficacy are more open to new ideas and more likely to try new tactics in behavior management. These teachers are also more likely to work collaboratively to promote the advancement of their students' intrinsic motivation and self-control while modifying their expectations to meet the specific needs of their students. There were two other conclusions Gaudreau et al. reached from their brief review. First, the greater sense of self-efficacy, the easier it is for teachers to ask their colleagues for help. Second, the more teachers believe they are supported, the more adaptable they are to selecting intervention techniques to managing a variety of students' challenging behaviors.

Psychological flexibility. The ability of teachers to approach behavioral challenges differently may depend on their personality traits such as originality and curiosity, open-mindedness, pliability, and understanding and accepting differences in other people ${ }^{[15]}$. Conversely, the characteristic of neuroticism may lead to teacher resistance and burnout ${ }^{[16]}$. It is no stretch to say that individuals who have control issues, are rigid, and take children's misbehavior personally would not make ideal teachers-certainly in terms of managing challenging behaviors. Conversely, individuals possessing high levels of psychological flexibility may be the most effective at changing their beliefs and openness to trying novel approaches.

Psychological flexibility is a term used in positive psychology to describe an individual's ability to modify responses to best match in any given situation. Block and Block $^{[17]}$ conducted a longitudinal study of ego-resilience from childhood to adulthood that parallels psychological flexibility and found that individuals with the egoresilient characteristic had a dynamic ability to momentarily change from typical reactions or preconceived notions to reactions and perceptions responsive to the immediate situation and, generally, to the inevitable varied and changing situations encountered in everyday life. Further, when people are open, receptive, and curious, they identify and pursue new knowledge and experiences and are inclined to accept the positive and negative feelings that often occur when confronting novel, complex, uncertain, and unpredictable stimuli. The essential issue is whether traits that predispose psychological flexibility in individuals can be nurtured or taught to those who are more psychologically rigid.

It may be more problematic for teachers to change their beliefs about, and tactics for, managing students' challenging behaviors. For example, if a student makes animal noises and the teacher sends the student to the office, but only to return and continue to make animal noises, then the teacher should change to an alternative strategy. One possible solution would be for the teacher not to turn in the direction of the disturbance but rather scan the classroom and identify three or four peers who are giving the student making animal noises the most attention. The teacher would take those peers aside and tell them she is writing their names on three by five cards and every time the student makes animal noises, she will turn to those four peers and if they are not looking at the offending student or saying anything to him, a tally mark would be made next to their names. The tally marks each represent one minute of free time at the end of class. This solution requires a significant paradigm shift for many teachers and represents the type of behavioral adaptability on the part of the teacher that we expect of students.

The question remains, can teachers make such changes? The answer is that some may be able to and some may not. There is some evidence that teachers keeping a daily log regarding their responses to students who display challenging behavior and then reflect on the relative success or failure of those interventions can help motivate change. Setting and evaluating goals for dealing with students' misbehavior positively may also facilitate change. Even so, the way teachers interpret misbehavior and react to it is so habitual and occurs at an unconscious level that change takes a tremendous amount of conscious effort. For example, if you asked a teacher to slow down her habitual cognitions and think of what she would be saying to herself when a student misbehaves, the two common thoughts would be "He shouldn't be doing that" and "He needs to stop." Those automatic self-statements immediately lead the teachers in a certain direction on how to react behaviorally to the student - namely by administering some negative consequence (e.g., verbal reprimand, timeout chair in the back of the room, student sitting in the hall, or being sent to the principal's office). But what if the first thought that popped into a teachers mind was "What is the reason he's doing that?" or "What does he want?" or "What is he getting from doing that?" Those 
questions, rather than the two previous statements, lead to different teacher behavior. The reason is because those questions are trying to answer what is the function, or purpose, of the student's misbehavior. Put another way, what is the student trying to communicate to me? Those questions lead to teacher behaviors that would be based on a functional behavioral assessment (FBA) framework, an issue expanded on in the next section.

\section{School practices that impede using effective behavior management}

The terms "practices" was purposely used in the above heading instead of "culture". School culture and climate have been the topic of numerous articles, books, and applied research. School culture is not the same as school climate. School culture typically refers to the long-term physical and social environment, as well as the values or beliefs of the school shared across individuals and time ${ }^{[18]}$. Gruenert ${ }^{[19]}$ noted that school culture is deeply rooted in a school, and can only be altered through systematic change over a long period of time. School climate, conversely, refers to the individual experiences and feelings teachers and students have regarding the school ${ }^{[20]}$. The term "practices" was used here because it refers to those operationalized behaviors that may stem from both school culture and climate, but are displayed on a daily basis such as how a teacher delivers a lesson or handles a student who is misbehaving. These practices can be instituted at the school-wide level such as through the use of positive behavior interventions and supports (PBIS).

\subsection{School-wide discipline}

There have been many school-wide discipline programs that have been used throughout the last several decades such as Assertive Discipline ${ }^{[21]}$ that was a popular approach during the 1970s and 1980s. Other similar approaches have been used by schools such as Cooperative Discipline, Active Student Involvement, Discipline Through Dignity, the Win-Win program, Think Time, and Behavior Intervention Support Team ${ }^{[11]}$. Recently, there has been an evolving and growing popularity of schools adopting multi-tiered systems of support (MTSS), typically operationalized as Response to Intervention (RTI) for academics and PBIS to address students' challenging behaviors. MTSS are based on a universal supports paradigm which addresses students who are struggling academically or behaviorally regardless of the presence or absence of a disability.

No matter whether a school conceptualizes a practice as RTI or PBIS, the underlying assumption is that they will benefit all students in a school and that all teachers must apply their tenants uniformly. It is important to examine a student population to understand how necessary these programs are for any given school and if they, ironically, may sometime prevent the application of individual teachers being able to effectively manage students' challenging behaviors. Figure 1 provides a "triangle" that is used as a common illustration for RTI and PBIS. However, instead of Figure 1 describing different levels or "tiers" of intervention intensity, it reflects the levels of "discipline" students' behaviors require. According to this triangle approximately $60 \%$ students do not need any structured school-wide discipline systems, although this percentage will vary depending on geographic, racial, and socioeconomic demographics. Nevertheless, these $60 \%$ of students are well-behaved, may require the occasional verbal reprimand or perhaps infrequently sent to a timeout chair. Their parents have raised them to respect school personnel and to behave appropriately while in school. Ironically, this assumption may contribute to the fact that few general education teacher training programs require a course in behavior management. The $35 \%$ group are students who would benefit from some level of a school-wide discipline program. They could make up some combination of traditional tier 1 or tier 2 of PBIS. The top of the pyramid are the 5\% who display the most challenging behaviors.

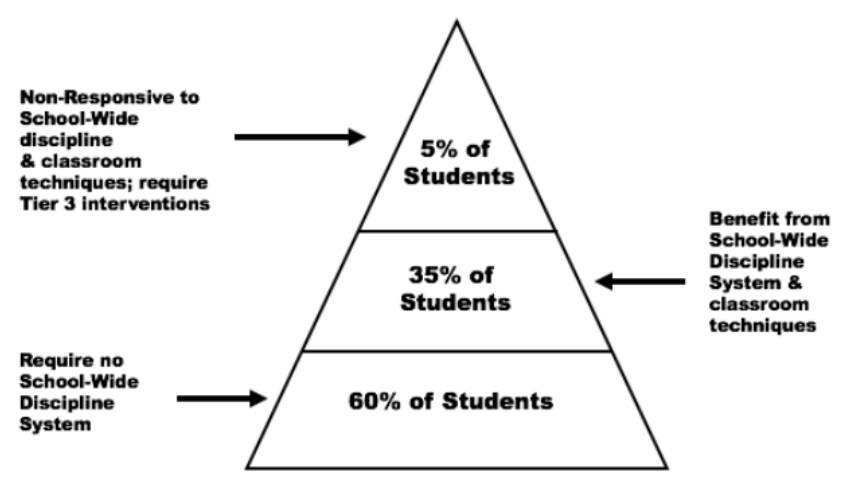

Figure 1. The discipline triangle

Contrast this discipline triangle in Figure 1 to the percentages of students who respond at the three levels of PBIS. According to Simonsen, Sugai and Negron ${ }^{[22]}$ approximately $80 \%$ of students who display inappropriate behaviors respond to tier 1 interventions with another $15 \%$ requiring additional interventions to behave appropriately (tier 2 )and the remaining 5\% displaying the most challenging behaviors requiring intensive individual interventions (tier 3). It is debatable how much of the $80 \%$ that Simonsen and colleagues believe respond to tier 1 actually need tier 1 at all, but what is clear-both "tri- 
angles" agree with $5 \%$ of students displaying the most challenging behaviors and needing the most intensive interventions. Here is the irony: $80 \%$ of students respond to tier 1 interventions, but $80 \%$ of discipline problems experienced by a school originate from only the $5 \%$ who display the most challenging behaviors ${ }^{[11]}$.

\subsection{Cost-benefit ratio and behavioral fallout}

It does not take an expert economist to understand that the effort a school puts into a school-wide program in terms of training, time, and resources that the cost-benefit ratio seems lopsided. Another irony is that school-wide programs typically are based on teachers being consistent and applying the techniques at each tier similarly. The irony is that the $5 \%$ with the most challenging behaviors, by definition, require teachers to do something different. That is, an "one-size-fits-all" mentality is a prescription for behavioral disaster. Another issue is that no matter how correctly and effectively schools implement PBIS, there will always be students with challenging behaviors in classrooms that teachers will have to deal with individually and most likely spontaneously. Even students receiving tier 3 - individual intensive interventions does not mean those students will automatically behave just as well in all situations and classes as students who need no school-wide disciplines program or even those who respond to tier 1 approaches. It is a forgone conclusion that teachers will be faced with dealing with those students in their classrooms and to think otherwise is simply fooling yourself. Further, the very nature of students with challenging behaviors is that one specific intervention will probably only work for two to three weeks before it has to be changed or modified. The reinforcers will either need to be changed, probably due to satiation, or the reinforcement delivery system will need to be changed because its novelty wears off. At that point, individual (teacher) and system (school) begin to diverge.

\subsection{Teacher versus system}

The term "students with challenging behaviors" has become part of the school vernacular. In fact, it has become part of the nomenclature in other settings and situations in which an adult can be heard saying that so-and-so's behavior is really challenging-whether it is a coach, camp counselor, or parent. It is important to understand that students with challenging behavior are defined through our behavior and not their behavior. Put another way, if what teachers were doing was working, then the student would no longer be considered a challenge. However, if a teacher is responding to a student's misbehavior in ways that are repeated regularly, then it is the teacher's behav- ior whose must change. This task becomes more difficult when a student receives tier 3 services in the form of an intensive individual intervention plan. The reason is because it is impossible for any individual plan to take into account the different personalities and interaction styles of teachers, the type of course content (e.g., a student likes history but not algebra), composition of other peers in a given classroom, and teachers' disciplinary styles. Human behavior is just too dynamic and modifiable given the variables described previously.

The reality is that teachers are expected to follow the structures of the school-wide system at all tiers. If a student on a tier 3 intervention is not responding or, more likely, actively misbehaving in a class, then the teacher is left with no other solutions to try. There will be two potential byproducts from this situation. First, the teacher will simply keep doing what the intervention plan indicates even when it is not working in that setting or context. After all, if the only tool you have is a hammer, then the entire world looks like a nail. Second, teachers will revert back to punitive and exclusionary practices. The punishment mentality, typically exemplified by exclusionary practices, is so strongly ingrained in the culture of schools that it becomes an easy alternative for reasons described previously.

It is truly amazing how strong the punishment ethos is among teachers as the following anecdote illustrates. Students who are in majors of special education or dual special and general elementary education at my institution are required to take my undergraduate behavior management course - typically the semester before their final practicum prior to their student teaching. Students, upon completing student teaching and close to graduation, are required to complete a capstone project. Students put together a portfolio of their student teaching experiences and then present how their coursework impacted on their student teaching practices by addressing two of the seven Council for Exceptional Children (CEC) special education preparation standards. Some students select the second standard, Learning Environments, which covers behavior management. One student selected this standard and explained how my behavior management course impacted her student teaching by describing a technique in which she would take away points when a student misbehaved. The irony is that one practice in my course is giving students tokens or points for displaying appropriate behavior for which they can later exchange for small activities or privileges. Within the span of two semesters, this student adopted negative rather than positive methods for managing behavior. The reason is that she was exposed, during her student teaching, to that negative, 
punitive approach and assimilated that culture-if for no other reason to affiliate.

No teacher wants to feel isolated in their school by engaging in practices that are counter to the prevailing culture. New teachers do not want to appear arrogant by describing techniques that older more veteran teachers either never heard of or are counter to their pedagogical ethos. It is human nature to want to be assimilated in a culture-especially one that includes individuals in the same profession. Research in social psychology and group dynamics has demonstrated these human traits through a variety of experiments and over many decades ${ }^{[23]}$. It is even harder for novice teachers to disagree with veteran teachers or administrators who they perceive to be in authoritative roles, as Stanley Milgram's ${ }^{[24]}$ classic study on obedience demonstrated.

\section{Conclusion}

I have suggested that managing students' challenging behaviors positive and effectively creates an improbable scenario for uniform success. I have reached this conclusion from 30 years of being a special education teacher, psychotherapist, professor at a research-one university, behavioral consultant to individual schools and school districts, author of several books to help teachers manage students' challenging behaviors more effectively, and conductor of workshops throughout the United States and Canada on the topic of managing resistance. Having said this as the backdrop for sharing my reflections and opinions appearing in this article, all is not lost. There are plenty of teachers at all levels who possess the trait of psychological flexibility and high self-efficacy that lend themselves to altering their behavior spontaneously when unexpected situations arise and also be open to trying new or novel methods for managing student behavior. In this regard, individuals in the teaching profession are no different from those in any discipline or line of work. I can offer some recommendations and thoughts for teachers to ponder that may help them to think outside of the box and expand their overall skills for managing students' behavior in a variety of situations. They appear in no particular order.

(1) Be personal with students but do not take their behavior personally;

(2) Trying and failing is not failing, it's assessment, never trying is failing;

(3) Think small: Behavior change is like a kaleidoscope, all one has to do is turn the tube a fraction of an inch, yet the entire pattern changes;

(4) Managing student behavior positively enhances re- lationships while dealing with it punitively inhibits relationships;

(5) Fair and equal are not the same thing;

(6) If what you are doing is not working, try something else;

(7) Reinforcement and punishment are defined based on their effects on behavior-if a consequence did not increase behavior it is not reinforcement and if a consequence did not decrease behavior it is not punishment;

(8) Students will communicate to us the best way to deal with them effectively;

(9) When a student misbehaves, ask yourself what does he want and how you can teach him an appropriate way to achieve it;

(10) We think we are watching everything students do, but we have a routine way of looking;

(11) Getting into a power struggle with a student is like mud wrestling a pig, you both get dirty and the pig loves it, and

(12) If a teacher asks a student to do something 100 times and the student refuses, who is the slow learner?

\section{References}

[1] Coalition for Psychology in Schools and Education. Report on the teacher needs survey. Washington, DC: American Psychological Association, Center for Psychology in the Schools and Education. 2006.

[2] Gaudreau N, Royer E, Frenette E, et al. Classroom behaviour management: The effects of in-service training on elementary teachers' self-efficacy beliefs. McGill Journal of Education, 2013, 48(2): 359-382. https://doi.org/10.7202/1020976ar

[3] Martin A, Linfoot K and Stephenson J. How teachers respond to concerns about misbehavior in their classroom. Psychology in the Schools, 1999, 36(4): 347-358. https://doi.org/10.1002/(SICI)1520-6807(199907)36: 4〈347::AID-PITS7 $\rangle$ 3.0.CO;2-G

[4] Skinner ME and Hales MR. Classroom teachers' explanations of student behavior: One possible barrier to the acceptance and use of applied behavior analysis procedures in schools. Journal of Educational \& Psychological Consultation, 1992, 3(3): 219-232. https://doi.org/10.1207/s1532768xjepc0303_2

[5] Dobbins N, Higgins K, Pierce T, et al. An analysis of social skills instruction provided in teacher education and in-service training programs for general and special educators. Remedial and Special Education, 2010, 31(5): 358-367. https://doi.org/10.1177/0741932509338363

[6] Romer N, Green AL and Cox KE. Educator perceptions of preparedness and professional development for implementation of evidence-based practices within a multi-tiered system of supports. School Mental Health: A Multidisciplinary Research and Practice Journal, 2018, 10: 122-133. https://doi.org/10.1007/s12310-017-9234-3 
[7] Vollmer LE, Gettinger M and Begeny JC. Training preservice general education teachers in response to intervention: A survey of teacher educators throughout the United States. Journal of Applied School Psychology, 2019, 35(2): 122145. https://doi.org/10.1080/15377903.2018.1528488

[8] Maag JW. Behavior management: From theoretical implications to practical applications (3rd). Boston, MA: Cengage Learning. 2018.

[9] Maag JW. Rewarded by punishment: Reflections on the disuse of positive reinforcement in schools. Exceptional Children, 2001, 67(2): 173-186. https://doi.org/10.1177/001440290106700203

[10] Kohn A. Punished by rewards: The trouble with gold stars, incentive plans, A's, praise, and other bribes. Boston, MA: Houghton Mifflin Harcourt. 1995.

[11] Maag JW. School-wide discipline and the intransigency of exclusion. Children and Youth Services Review, 2012, 34(10): 2094-2100. https://doi.org/10.1016/j.childyouth.2012.07.005

[12] Axelrod S. What's wrong with behavior analysis? Journal of Behavioral Education, 1996, 6: 247-256. https://doi.org/10.1007/BF02110126

[13] Maag JW. Challenging classroom behaviors: Overcoming resistance through uniquely audacious interventions. Port Chester, NY: Dude Publishing. 2012.

[14] Bandura A. Self-efficacy: Toward a unifying theory of behavioral change. Psychological Review, 1977, 84(2): 191-215. https://doi.org/10.1037/0033-295X.84.2.191

[15] Lee SY and Min J. The profiles of creative potential and personality characteristics of adult professionals. Creativity Research Journal, 2016, 28(3): 298-309. https://doi.org/10.1080/10400419.2016.1195634
[16] Kokkinos CM. Job stressors, personality and burnout in primary school teachers. British Journal of Educational Psychology, 2007, 77(1): 229-243. https://doi.org/10.1348/000709905X90344

[17] Block J and Block JH. Venturing a 30-Year Longitudinal Study. American Psychologist, 2006, 61(4): 315-327. https://doi.org/10.1037/0003-066X.61.4.315

[18] Çakiroǵlu Ü, Akkan Y and G'uven B. Analyzing the effect of web-based instruction applications to school culture within technology integration. Educational Sciences: Theory \& Practice, 2012, 12: 1043-1048.

[19] Gruenert S. School culture, school climate: They are not the same thing. Principal, 2008, 56-59. http://www.naesp.org/resources/2/Principal/2008/M-Ap56. pdf

[20] School Climate Council. The school climate challenge: Narrowing the gap between school climate research and school climate policy, practice guidelines and teacher education policy. 2007.

http://schoolclimate.org/climate/documents/school-climate -challenge.pdf

[21] Canter L and Canter M. (1992). Assertive discipline: A takecharge approach for today's educator. Santa Monica, CA: Canter and Associates.

[22] Simonsen B, Sugai G and Negron M. Schoolwide positive behavior support: Primary systems and practices Teaching Exceptional Children, 2008, 40(6): 32-40. https://doi.org/10.1177/004005990804000604

[23] Aronson E, Wilson TD, Akert RM, et al. Social psychology (9th edition).Upper Saddle River, NJ: Pearson. 2015.

[24] Milgram S. Behavioral study of obedience. Journal of Abnormal and Social Psychology, 1963, 67(4): 371-378. https://doi.org/10.1037/h0040525 